\title{
P03-205
}

\section{TO BE OR NOT TO BE}

\section{J. Tavares, E. Soares}

Centro Hospitalar Psiquiátrico de Lisboa, Lisbon, Portugal

From the trema stage defined by Conrad to the unique place that delusional perception occupies in classical psychopathology, the early stages of schizophrenia have always attracted the interest of philosophers and phenomenologists as well as psychopathologists. Pre-delusional state has been understood, since the nineteenth century, as a pervasive disorder affecting cognition, affect, conscioussness or motility. This pathological matrix transports patients to a place where they are not able to relate the significances to the common intersubjective world, and are trapped in self-referential meanings. The mistery that surrounds this experience becomes a challenge to patients, doctors and particularly to their empathic relationship.

By presenting a clinical case we wish to illustrate how clinical practice is in fact in a hazardous intersection of different angles of analysis of the reality of human behavior and how phenomenological, empirical and biological approaches intersect explaining psychiatric illness in a hybrid way. Furthermore we wish to review the historical and phenomenological approaches to the early stages of schizophrenia, and confront them with more recent empirical and epidemiological data. 